\title{
MENGATASI LIMPASAN BANJIR DENGAN METODE MODIFIKASI DAN REROUTE SALURAN
}

\section{(Overcoming Flood Flows With The Modification And Re-Route Channel Methods)}

\author{
Sulardi \\ Sekolah Tinggi Teknologi Minyak dan Gas (STT Migas), Balikpapan \\ Jl. Soekarno - Hatta KM.8, Transad, Karang Joang Balikpapan 76126, Kalimantan Timur, Indonesia \\ Email : sulardikm61@yahoo.com
}

Diterima: 22 Juli 2019; Direvisi: 4 Oktober 2019; Disetujui: 25 November 2019

\begin{abstract}
ABSTRAK
Salah satu permasalahan yang dihadapi di kawasan kilang pengolahan minyak Balikpapan adalah masalah limpasan banjir dari kawasan pemukiman penduduk dan dari lingkungan komplek perumahan pekerja kedalam area kilang. Limpasan banjir menggenangi instalasi perpipaan dan peralatan operasi kilang yang dapat mengganggu operasi kilang. Penelitian ini bertujuan untuk memberikan gambaran faktor dan penyebab masalah limpasan banjir di kilang serta metode perbaikannya. Penelitian ini menggunakan metode penelitian aplikasi dengan pendekatan studi kasus penanganan masalah limpasan banjir kilang. Hasil penelitian menunjukan bahwa faktor dan penyebab limpasan banjir kilang Balikpapan adalah faktor alat, yakni dimensi dan konfigurasi saluran drainase yang tidak sesuai serta masih tergabungnya saluran pembuangan air dari luar kilang dengan saluran air dalam kilang. Metode perbaikan yang dilakukan adalah dengan melakukan pemisahan saluran air dari luar kilang dibuat terpisah dengan saluran air buangan dari dalam kilang dan memodifikasi saluran eksisting dengan dimensi dan konfigurasi saluran yang sesuai. Hasil penelitian menunjukan bahwa metode perbaikan dengan pemisahan saluran dari luar kilang dan dari dalam kilang terbukti efektif dan cocok digunakan untuk mencegah dan mengendalikan limpasan banjir di area kilang utara. Hasil penelitian ini merekomendasikan bahwa keberhasilan metode penanganan permasalahan ini dapat direplikasi untuk mengatasi permasalahan sejenis.
\end{abstract}

Kata kunci : Limpasan banjir, modifikasi, re-route saluran dainase

\begin{abstract}
One of the problems in the Balikpapan oil refinery area is flood runoff from residential areas and from the neighborhoods of workers' housing complexes to the refinery area. Flood runoff inundates pipeline installations and refinery operating equipment which can disrupt refinery operations. This study aims to provide an overview of the factors and causes of flood runoff problems in refineries and their improvement methods. This study uses an application research method with a case study approach to handling refinery runoff problems. The results showed that the factors and causes of the Pertamina Balikpapan refinery flood runoff were tool factors, namely the dimensions and configuration of inappropriate drainage channels and the incorporation of water drains from outside the refinery with drains for refineries. The method of repair that is done is by separating the drains from outside the refinery to be made separate from the sewerage from inside the refinery and modifying the existing channel with the appropriate dimensions and channel configurations. The results showed that the method of repair with the separation of channels from outside the refinery and from the refinery proved to be effective and suitable to be used to prevent and control flood runoff in the northern refinery area. The results of this study recommend that the success of this problem handling method can be replicated to overcome similar problems.
\end{abstract}

Keywords: Flood runoff, modification, re-routing of dainase channels 


\section{PENDAHULUAN}

Kilang Pertamina Unit V (RU V) Balikpapan adalah satu diantara tujuh kilang yang dioperasikan Pertamina yang memiliki tugas untuk mengolah dan menyediakan bahan bakar minyak untuk kawasan Indonesia Tengah dan Indonesia Timur. Kilang Balikpapan dengan luasan $\pm 1.720 .000 \mathrm{~m} 2$ dibagi menjadi dua area operasi, yakni area kilang utara aang terdiri dari area tangka timbun, area kilang unit pengolah minyak dan unit penunjangnya. Sedangkan area kilang selatan adalah area tangka timbun untuk bahan bakar minyak dan fasilitas instalasi pengapalan produk minyak dan gas. Permasalahan yang dihadapi adalah terjadinya limpasan banjir air permukaan dari badan air Sungai Karang Anyar, limpasan dari Jalan A. Yani, limpasan dari kawasan perumahan Total Indonesia, limpasan dari kawasan perumahan Dubbs dan limpasan dari saluran drainase Jalan Yos Sudarso (Sulardi, 2015). Dampaknya adalah terendamnya fasilitas perpipaan dan peralatan operasi kilang, terganggunya operasi kilang, tingginya beban unit pengolah air limbah kilang Pertamina dan beban moral bagi lingkungan pekerja Pertamina. Terhadap permasalahan tersebut dilakukan tindakan pencegahan dengan meninggikan tanggul-tanggul banjir ditepian saluran drainase kilang area utara (Sulardi, 2014). Tetapi hal tersebut tidak menyelesaikan permasalahan dengan tuntas karena pada saat terjadi hujan lebat yang cukup lama maka limpasan banjir kembali terjadi dan mengakibatkan hal yang sama sebagaimana telah diuraikan diatas.

Diprediksi faktor penyebab permasalahan adalah faktor bahan (material) dan faktor alat (equipment) yakni adanya limpasan air permukaan dari kawasan Sungai Karang Anyar yang melimpas ke area Komplek Perumahan Pertamina Parikesit dan kawasan kilang utara. Sedangkan faktor alat adalah bentuk dan konfigurasi saluran drainase yang tidak sesuai (sub standard). Penyebab limpasan banjir di area kilang adalah dimensi dan konfigurasi saluran drainase tidak sesuai dengan fungsi dan peruntukannya sehingga pada saat terjadi limpasan dalam volume yang besar tidak mampu ditampung dan dialirkan oleh fasilitas saluran drainase yang ada.

Untuk itulah maka penelitian ini penting untuk dilakukan guna menemukan jawaban atas permasalahan limpasan banjir di area kilang Pertamina Balikpapan sehingga permasalahan tersebut dapat ditangani dengan baik, aman dan terulang kembali. Tujuan yang hendak dicapai penelitian ini adalah untuk memberikan gambaran faktor, penyebab dan gambaran metode pengendalian limpasan banjir diarea kilang pengolahan minyak PT. Pertamina Balikpapan

Ruang lingkup penelitian ini meliputi sistim saluran drainase luar kilang utara dan sistim drainase luar kilang selatan. Sistim saluran drainase kilang utara adalah saluran drainase yang diperuntukan bagi limpasan banjir permukaan yang berasal dari kawasan perumahan, perkantoran, kawasan pemukiman dan saluran drainase sepanjang jalan umum diluar kilang area utara dan dialirkan langsung ke pelepasan (outfall) di Teluk Balikpapan. Sistim saluran drainase kilang selatan adalah saluran drainase yang diperuntukan guna mengalirkan limpasan air permukaan dari kawasan perumahan Pertamina Dubbs, Pancur, Volker, kawasan perumahan Pertamina APT dan saluran drainase sepanjang Jalan Yos Sudarso. Sistim saluran air limbah diarea kilang tidak dibahas pada penelitian ini karena spesifikasi dan karakteristiknya berbeda dan metode pengelolaannya telah diatur sedemikian rupa menggunakan unit pengolah air limbah (effluent water treatment plant).

Asumsi penelitian adalah bahwa (1) Terdapat perbedaan spesifikasi antara limpasan air hujan dan air buangan didalam area kilang (2) limpasan air hujan aman untuk dialirkan dan dibuang langsung ke perairan bebas (3) air limbah dari kawasan kilang terkontaminasi bahanbahan yang dapat mencemari lingkungan dan dilakukan netralisir dengan metode pengolahan limbah terlebih dahulu hingga memenuhi batas ambang batas aman untuk dibuang ke perairan bebas (4) limpasan air hujan dari area luar kilang jumlahnya sangat besar, jika menyatu dengan sistim aliran saluran drainase dalam kilang maka akan sangat membebani unit pengolahan limbah air kotor (effluent water treatment plant) (5) spesifikasi, bentuk dan dimensi saluran 
drainase sesuai kaidah bahwa semakin kearah hilir maka volume aliran akan semakin besar oleh karena itu dimensi saluran drainasenya semakin kearah hilir semakin besar (Peraturan Menteri Pekerjaan Umum No. 12/PRT/M/2014 (2014). Dengan asumsi tersebut maka pemisahan antara limpasan air hujan dari luar kilang dengan buangan air kotor dari dalam kilang sangat penting untuk dilakukan.

Pengamatan terhadap sistim saluran drainase luar kilang utara telah dilakukan perbaikan dengan melakukan normalisasi saluran dan melakukan redimensi saluran eksisting (Sulardi, 2014). Outfall saluran drainase yang semula berbentuk "U" dengan ukuran 6x3 meter dimodifikasi menjadi bentuk trapezium terbalik dengan dimensi lebar atas saluran 24 meter, lebar bawah 20 meter, kedalaman saluran 1,6 meter dan dilengkapi dengan saluran minim flow bentuk trapesium dengan lebar atas 6 meter, lebar dasar 5 meter dan kedalaman saluran $50 \mathrm{Cm}$. Selain itu perbaikan juga dilakukan dengan meninggikan tanggul jagaan banjir diatas tanggul banjir eksisting setinggi $30 \mathrm{Cm}$ dengan material beton bertulang.

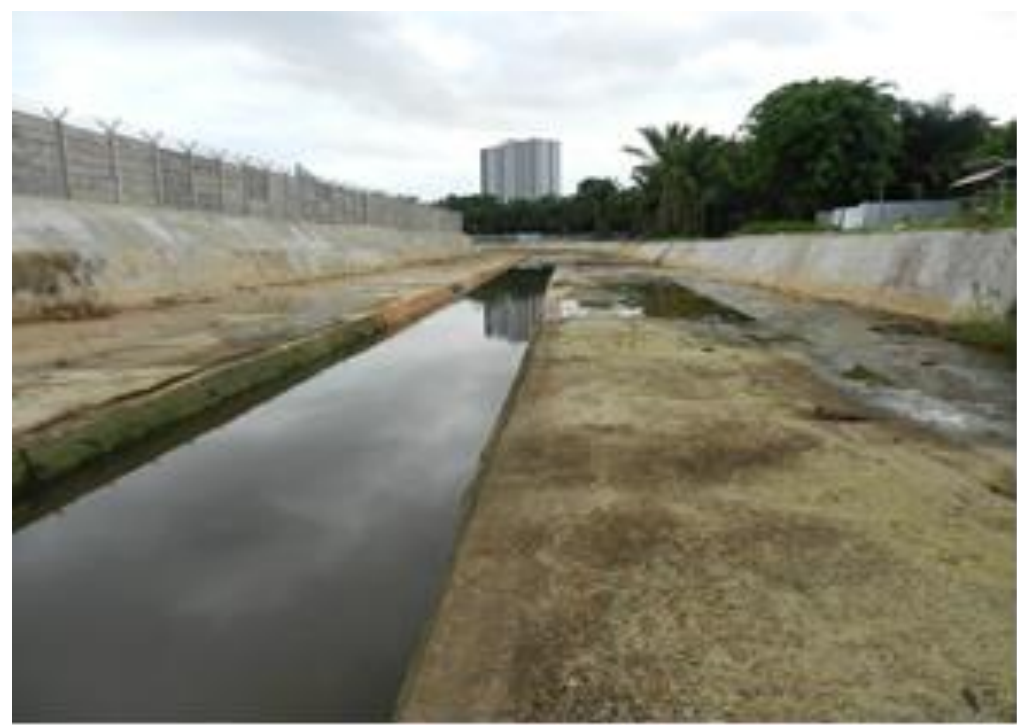

Gambar 1. Saluran drainase kilang utara setelah perbaikan

(Sumber : Sulardi, 2015)

Pada saat ini pekerjaan perbaikan saluran drainase telah selesai, saluran drainase telah berfungsi dengan baik dan metode perbaikan yang dipergunakan telah dapat mengatasi masalah limpasan banjir permukaan di area kilang utara. Fokus penanganan permasalahan penelitian pada saat ini adalah pada metode perbaikan saluran drainase luar kilang area selatan.

\section{METODE PENELITIAN}

\section{Lokasi Penelitian}

Lokasi penelitian adalah sistim saluran drainase luar kilang utara dan sistim saluran drainase kilang selatan Pertamina Balikpapan. Kedua sistim saluran ini sangat penting sebagai alat pengendali limpasan banjir air permukaan dari luar kilang agar tidak masuk ke sistim saluran air didalam kilang. 


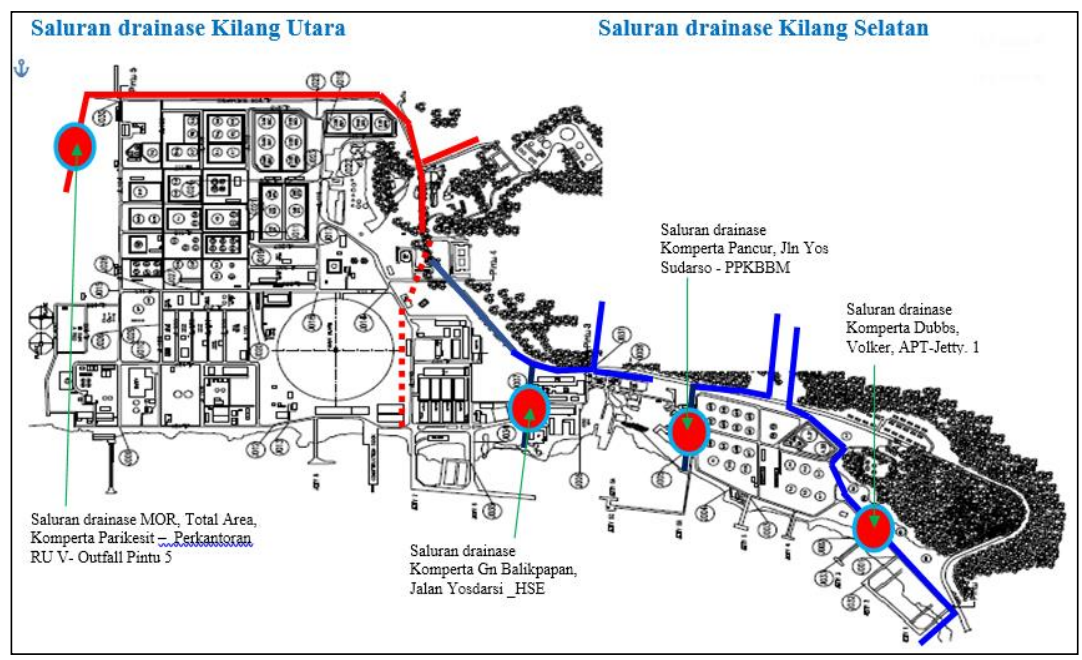

Gambar 2. Peta lokasi penelitian

(Sumber : Sulardi, 2014)

\section{Metode Penelitian}

Metode penelitian ini menggunakan metode penelitian aplikasi atau penelitian terpakai dengan metode pendekatan studi kasus, yakni studi kasus metode pengendalian limpasan banjir di area utara (Sulardi, 2014) dan area selatan kilang Balikpapan (Sulardi, 2015). Program perbaikan sistim saluran drainase luar kilang utara dan sistim saluran drainase luar kilang selatan dilakukan secara bertahap, dimana program perbaikan saluran drainase luar kilang utara dikerjakan terlebih dahulu dan keberhasilan penanganan masalah (success story) ini dijadikan sebagai pembelajaran (lesson learnt) untuk direplikasi pada program perbaikan sistim drainase luar kilang selatan (Sulardi, 1997). Pembelajaran yang diperoleh dari keberhasilan penanganan masalah limpasan di area kilang utara adalah bahwa sistim saluran drainase dari area luar kilang yakni dari area perumahan, perkantoran dan pemukiman masyarakat harus dibuat terpisah dari sistim saluran drainase dalam kilang agar limpasan banjir dari luar kilang tidak membebabni sistim drainase didalam kilang.

Fokus penanganan masalah limpasan banjir di area kilang selatan ini adalah meliputi penanganan (1) Sistim saluran drainase area perumahan Komperta Dubbs, Komperta Pancur, Komperta Volker, perumahan Komperta APT dan saluran drainase Jalan Yos Sudarso (2) sistim saluran drainase area perumahan Komperta Gunung Balikpapan dan Jalan Yos Sudarso (3) sistim saluran drainase area Kantor Besar Pertamina RU V Balikpapan dan area perumahan Komperta T\&T. Ketiga saluran ini adalah saluran drainase dari luar area kilang yang kemudian bergabung dengan saluran drainase didalam kilang area selatan. Dengan masih bergabungnya limpasan air permukaan dari ketiga area komplek perumahan Pertamina (Komperta) tersebut maka pada saat terjadi hujan akan sangat membebani kapasitas mampu layan saluran drainase didalam area kilang selatan. Untuk itu dilakukan mapping terhadap masing-masing saluran drainase tersebut sebagai bahan acuan untuk melakukan modifikasi bentuk, dimensi dan konfigurasi saluran drainase didalam area kilang selatan. Metode penelitian dilakukan dengan pengamatan visual, dokumentasi dan pengukuran terhadap kondisi masing-masing saluran drainase di area luar kilang tersebut.

\section{Kajian Perubahan}

Program perbaikan saluran drainase luar kilang selatan pada tahap pertama diawali dengan tahap pembuatan kajian enjiniring dan enjiniring desain (management of change) (Sulardi, 2016, 2017). Management of change adalah bentuk kajian enjiniring terhadap fasilitas, bangunan, peralatan dan sistim proses eksisting yang akan dilakukan perubahan dan perubahan 
yang dilakukan merubah spesifikasi, proses, bentuk, dimensi dan konfigurasi kondisi eksisting sehingga hasil kajian enjiniring dapat menggambarkan spesifikasi yang baru, gambaran proses yang baru, bentuk, dimensi dan konfigurasi yang baru yang memiliki manfaat yang lebih baik dari aspek panca mutu (quality, cost, delivery, safety dan moral). Hasil kajian enjiniring ini selanjutnya dituangkan dalam bentuk gambar desain sebagai panduan pada pelaksanaan pekerjaan perbaikan di lapangan. Kajian enjiniring merupakan salah satu syarat dapat dilakukannya pekerjaan modifikasi struktur bangunan, sistim peralatan atau sistim proses dengan tetap mempertimbangan aspek kehandalan, kemanfaatan dan pengendalian terhadap bahaya proses yang ada. Kajian perubahan yang dilakukan terhadap sistim saluran drainase dalam kilang ini adalah meliputi perubahan bentuk, dimensi dan konfigurasi saluran dengan mempertimbangkan bahwa jika tidak dilakukan perubahan maka potensi limpasan banjir permukaan akan sering terjadi dan potensi sering terganggunya operasional kilang dan pencemaran lingkungan perairan.

Hasil kajian perubahan (MOC) mencakup uraian singkat permasalahan, usulan perubahan, kajian perubahan secara teknis dan analisa bahaya proses. Hasil kajian perubahan ini selanjutnya sebagai dasar untuk pembuatan gambar desain dan penyusunan rekomendasi perubahan. Rekomendasi Rekomendasi perubahan dan drawing sebagai dasar pembuatan ruang lingkup pekerjaan perbaikan dan penyusunan kerangka acuan kerja (KAK) pekerjaan modifikasi saluran drainase di area kilang selatan. MOC, rekomendasi perubahan dan KAK digunakan sebagai dasar penentuan rencana mutu pekerjaan (quality plan) dan syarat keberterimaan hasil pekerjaan (quality assurance).

\section{HASIL DAN PEMBAHASAN}

Hasil pengamatan terhadap bentuk, dimensi dan konfigurasi saluran drainase hasil perbaikan menunjukan bahwa hulu saluran drainase Komperta Gunung Balikpapan - HSE, bermuara dari seluruh kawasan Komperta Gunung Balikpapan, kawasan Gunung Teknik dan kawasan Jalan Yos Sudarso dengan panjang saluran drainase 870 meter, dengan dimensi saluran 40x60 Cm dengan bentuk saluran "U" terbuat dari pasangan bata. Ketiga saluran tersebut terinterkoneksi dengan bak kontrol ukuran 80x80x100 $\mathrm{Cm}$ dan dialirkan dengan melalui culvert pipa baja diameter 30 Inch dibawah ruas lapis perkerasan Jalan Yos Sudarso menuju kearea kilang selatan. Diarea dalam kilang aliran dari culvert pipa baja tersebut dialirkan dengan saluran terbuka ukuran $60 \times 70 \mathrm{Cm}$ menuju area pipe rack (instalasi perpipaan), menyatu dengan saluran drainase kawasan perpipaan dengan ukuran saluran drainase 70x80 $\mathrm{Cm}$ dan selanjutnya dialirkan ke hilir saluran disisi selatan kantor HSE dengan saluran terbuka dari pasangan bata bentuk "U" berukuran 100x100 Cm.

Saluran drainase kawasan Komperta Pancur-PPKBBM sepanjang 568 meter bermuara dikawasan Komplek perumahan Pertamina Pancur TVRI, bergabung dengan saluran darinase dari kawasan perumahan Gunung Teknik dan dialirkan ke saluran drainase di sisi timur Jalan Yos Sudarso dengan dimensi saluran drainase 50x60 $\mathrm{Cm}$ dan terinterkoneksi dengan saluran drainase darai kawasan Gunung Balikpapan dengan bak kontrol ukuran 80x80x100 Cm dan dialiran melalui culvert pipa baja ukuran 30 Inch dibawah lapis perkerasan ruas Jalan Yos Sudarso menuju ke dalam area kilang selatan. Didalam area kilang aliran dari culvert tersebut dialirkan dengan saluran terbuka ukuran $60 \times 70 \mathrm{Cm}$ menuju ke area pipe rack (instalasi perpipaan), menyatu dengan dengan saluran drainase kawasan instalasi perpipaan dan dialirkan ke outfall di area PPKBBM dengan saluran terbuka dari pasangan bata dengan ukuran 100x100x100 Cm.

Saluran drainase kawasan Komperta Dubbs-Jetty 1 sepanjang 935 meter bermuara dikawasan Komplek perumahan Pertamina Gunung Dubbs dengan ukuran 40x40 Cm, bergabung dengan saluran darinase dari kawasan perumahan Pertamina Volker, dimana kedua saluran drainase bertemu pada bak kontrol berukuran 60x60x80 $\mathrm{Cm}$ dan dialirkan dengan 
culver pipa baja ukuran 24 Inch dibawah lapis perkerasan ruas Jalan Volker menuju ke Jalan Yos Sudarso dan dialirkan kedalam area kilang dengan culvert pipa baja 30 Inch dibawah lapis perkerasan Jalan Yos Sudarso. Didalam area kilang aliran dari culvert tersebut dialirkan dengan saluran terbuka ukuran $70 \times 70 \mathrm{Cm}$ menuju ke area pipe rack (instalasi perpipaan), menyatu dengan dengan saluran drainase kawasan instalasi perpipaan dan dialirkan ke outfall melalui oil catcher. Pada kondisi hujan aliran langsung dibuang kelalut, sedang pada kondisi normal aliran dialirkan melalui oil catcher terlebih dahulu, dinetralisir dengan penambahan injeksi bahan kimia tertentu dan dibuang ke outfall melalui pintu kerek (slog gate).

Besarnya debit aliran limpasan banjir pada saluran drainase dipengaruhi oleh luasan daerah tangkapan air (catchment area), besarnya resapan aliran air hujan dan air permukaan, bentuk, dimensi, kapasitas dan konfigurasi saluran drainase. Berdasarkan data peta area kilang dan kawasan penunjangnya diketahui masing-masing daerah tangkapan air (catchment area) untuk masing-masing saluran drainase area kilang utara dan area kilang selatan tersaji pada Tabel 1.

Tabel 1. Daerah tangkapan air area kilang utara dan selatan

\begin{tabular}{lcc}
\hline \multicolumn{1}{c}{ Area } & Luas $(\mathrm{Ha})$ & Luas $\left(\mathrm{Km}^{2}\right)$ \\
\hline Kilang utara & 8.265 & 0.083 \\
Dubbs, Volker, APT, Kilang & 3.275 & 0.033 \\
Pancur, Jl.Yos & 1.275 & 0.013 \\
Sudarso,Kilang & & \\
$\begin{array}{l}\text { Gn.Bpn, Jl.Yos Sudarso, } \\
\text { Kilang }\end{array}$ & 1.850 & 0.018 \\
$\quad$ Total & 14.650 & 0.147 \\
\hline Sumber: Sulardi $(2014)$ & &
\end{tabular}

Sumber : Sulardi (2014)

Daerah tangkapan air adalah daerah geografis dengan batas punggung perbukitan yang merupakan satu kesatuan antara sungai dan anak-anak sungainya dari hulu ke hilir berupa danau atau laut. (Kodoatie dan Sjarief, 2010, dalam MA Nugraha, 2014). Dalam penelitian ini, catchment area telah ditentukan berdasarkan berdasarkan tata letak masing-masing kawasan komplek perumahan, perkantoran, Jalan raya dan kawasan kilang Pertamina RU V Balikpapan. Masing-masing kawasan ini telah memiliki sistim saluran drainase yang telah ditata sedemikian rupa dan merupakan salah satu kawasan percontohan sistim saluran drainase di kota Balikpapan.

Sistim saluran drainase dari area Komperta Gunung Dubbs, Komperta Volker, Komperta APT dan saluran drainase Jalan Yos Sudarso pada saat ini telah dibuatkan saluran drainase tersendiri diluar fasilitas instalasi perpipaan proses (pipe rack) untuk mencegah terkontaminasinya air permukaan dari luar kilang dengan limbah air kilang. Saluran drainase ini ditempat dikaki lereng tanggul pagar kilang dengan konstruksi beton bertulang kedap air dengan bentuk saluran " $U$ " berukuran 1,8 x 2,0 meter dengan kelandaian saluran 7o, diinterkoneksi dengan saluran drainase dikiri dan kanan area kilang selatan dan dilakukan modifikasi pembesaran saluran drainase menjadi ukuran 2,0x2,4 meter dan pembuatan saluran pelepasan (outfall) ke perairan Teluk Balikpapan dengan dimensi 1,80x2,60 meter dengan material beton bertulang. 


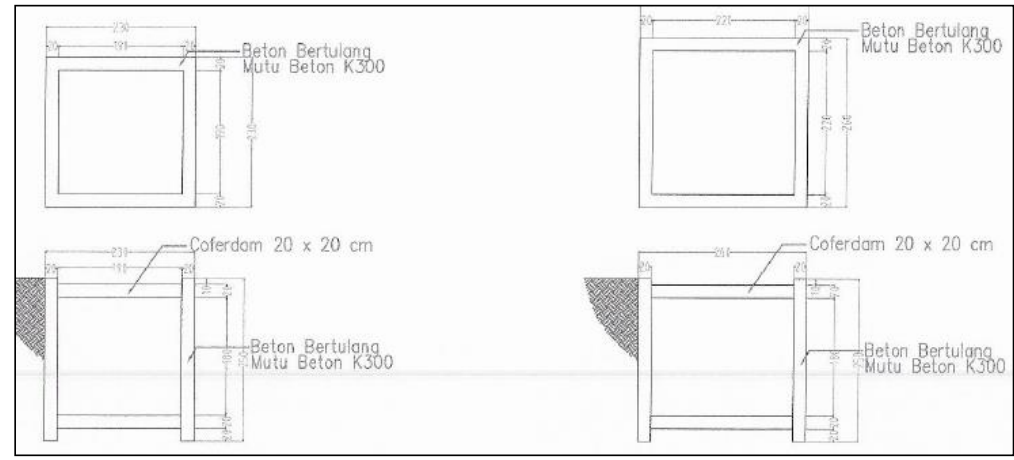

Gambar 3. Dimensi saluran drainase Komperta Volker-Jetty.1

(Sumber : Sulardi, 2016)

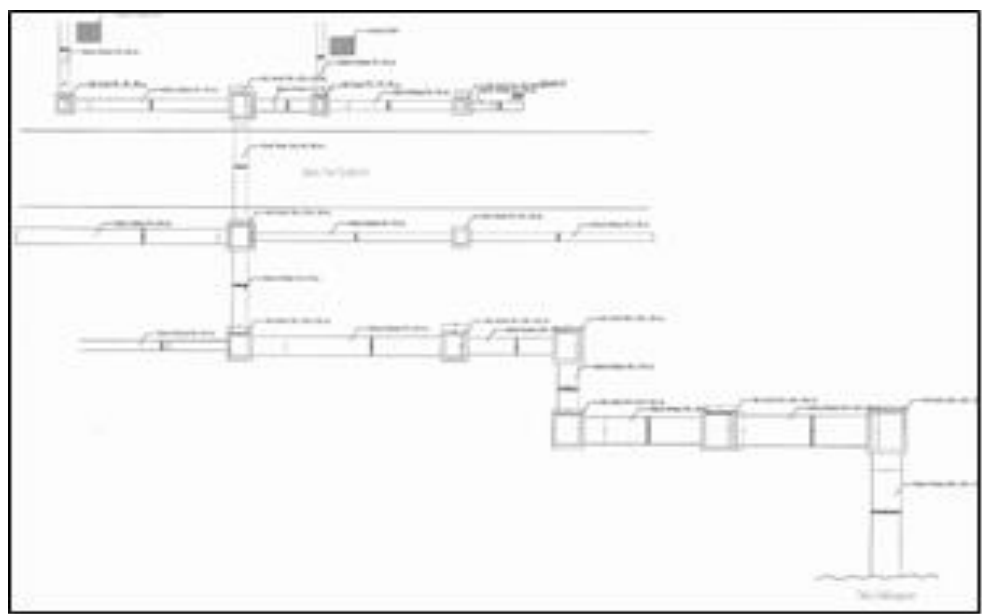

Gambar 4. Peta saluran drainase Komperta Volker-Jetty.1

(Sumber : Sulardi, 2016)

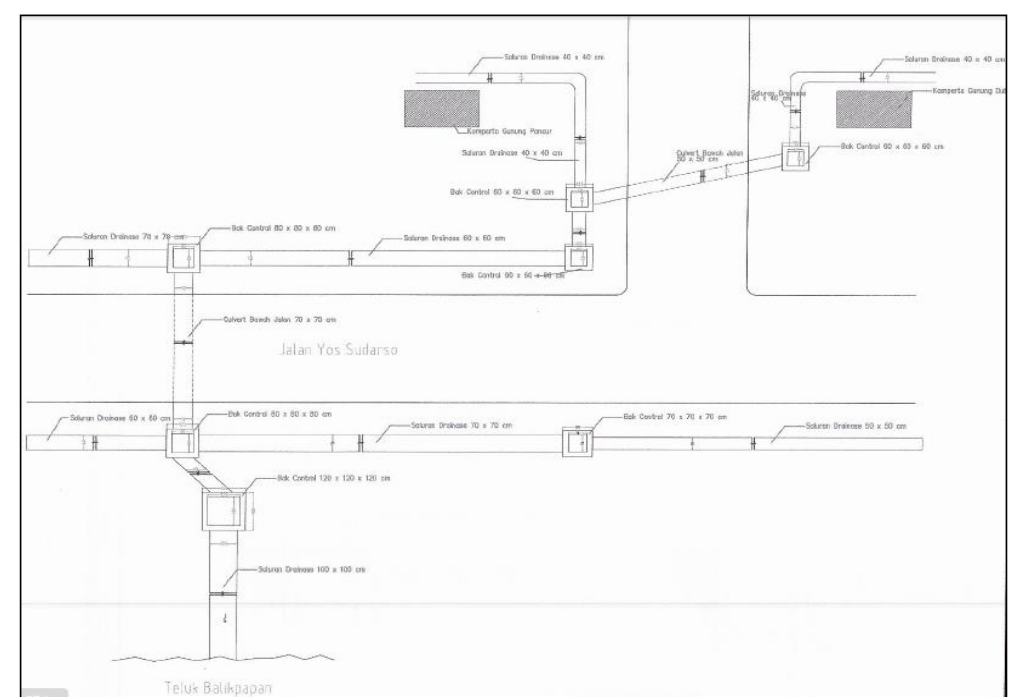

Gambar 5. Peta saluran drainase Gn.Pancur - PPKBBM (Sumber : Sulardi, 2016) 


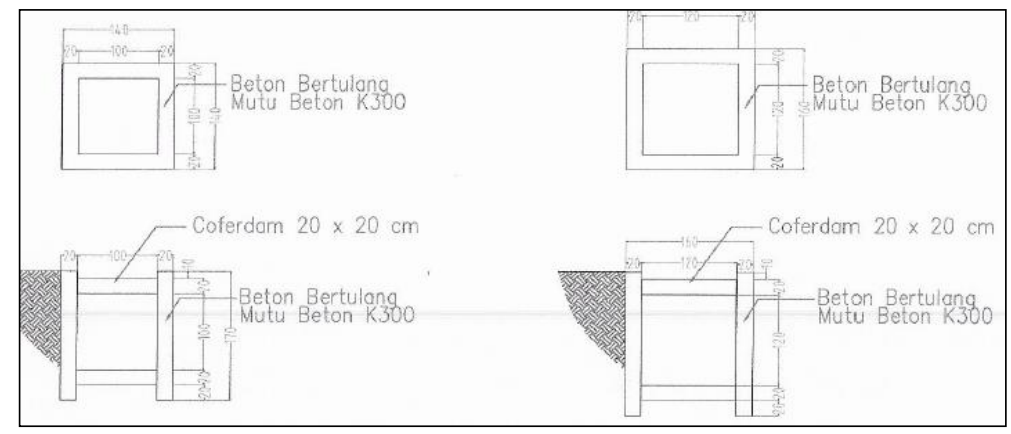

Gambar 6. Dimensi saluran drainase Gn.Pancur - PKBBM

(Sumber : Sulardi, 2016)

Sistim saluran drainase area perumahan Komperta Gunung Pancur, Komplek Perumahan Gunung Teknik dan saluran drainase Jalan Yos Sudarso saat ini dialirkan ke saluran drainase melalui area pipe rack dengan saluran pasangan bata $80 \times 80 \mathrm{Cm}$, dihandling di oil catcher untuk dipisahkan kandungan minyaknya dan air buangan yang telah dinetralisir dibuang ke pelepasan Teluk Balikpapan. Modifikasi yang dilakukan adalah memindahkan saluran drainase keluar dari area pipe rack, memperbesar dimensi saluran menjadi 1,60 x 2,10 meter dengan material beton bertulang dan membuat pintu kontrol pelepasan (outfall) saluran drainase. Modifikasi ini cukup mudah dan praktis karena antara kawasan komplek perumahan, kawasan perkantoran, jalan dengan permukaan tanah diarea kilang selatan beda tingginya sangat besar sehingga pengaliran dengan metode grafitasi akan sangat mudah.

Sistim saluran drainase area perumahan Komperta Gunung Balikpapan dan saluran drainase Jalan Yos Sudarso saat pada saat ini telah dilakukan modifikasi dengan memindahkan saluran drainase diluar dari area pipe rack, memperbesar dimensi saluran menjadi $1,80 \times 2,00$ meter dengan material beton bertulang dan didalam area kilang saluran drainase ini terinterkoneksi dengan saluran drainase dari kawasan Kantor Besar Pertamina dan saluran drainase kawasan Komperta T\&T menuju ke outfall diarea perkantoran HSE.

Sistim saluran drainase area Kantor Besar Pertamina RU V Balikpapan, Area Komperta Long Ikis dan area perumahan Komperta T\&T saat ini masih menyatu dengan saluran drainase di area pipe rack. Perubahan dan modifikasi yang akan dilakukan adalah dengan memisahkan saluran drainase dari area pipe menjadi saluran drainase khusus dari area luar kilang, memasang bak kontrol dan sedimen trappe, memperbesar dimensi saluran drainase eksisting menjadi 1,80x2,0 meter dengan material beton bertulang mutu beton $\mathrm{K} 300$ dan interkoneksi dengan saluran induk menuju ke HSE-Outfall.

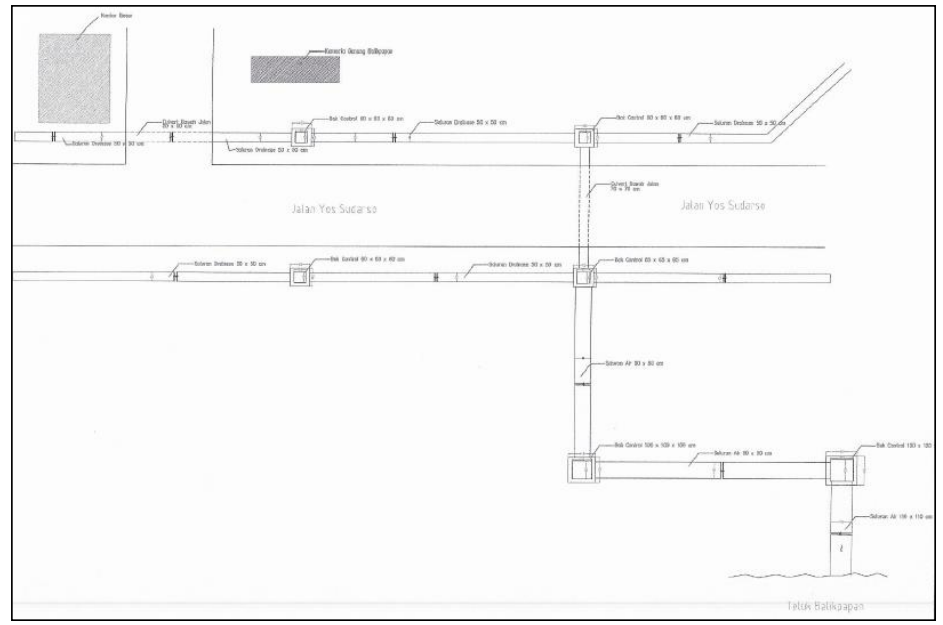

Gambar 7. Peta saluran drainase Komperta Gn.Balikpapan-HSE (Sumber : Sulardi, 2017) 


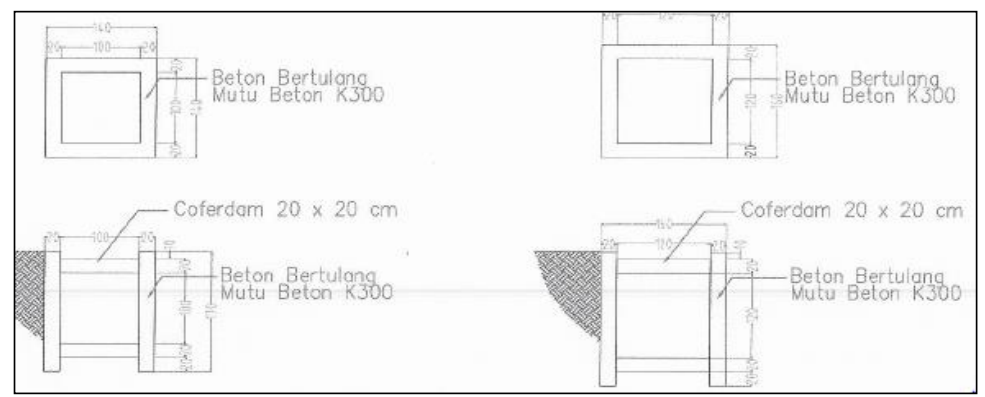

Gambar 8. Dimensi saluran drainase Gn.Balikpapan-HSE (Sumber : Sulardi, 2017)

Asumsi penelitian adalah bahwa (1) Terdapat perbedaan spesifikasi antara limpasan air hujan dan air buangan didalam area kilang (2) limpasan air hujan aman untuk dialirkan dan dibuang langsung ke perairan bebas (3) air limbah dari kawasan kilang terkontaminasi bahanbahan yang dapat mencemari lingkungan dan dilakukan netralisir dengan metode pengolahan limbah terlebih dahulu hingga memenuhi batas ambang batas aman untuk dibuang ke perairan bebas (4) limpasan air hujan dari area luar kilang jumlahnya sangat besar, jika menyatu dengan sistim aliran saluran drainase dalam kilang maka akan sangat membebani unit pengolahan limbah air kotor (effluent water treatment plant). Dengan asumsi tersebut maka pemisahan antara limpasan air hujan dari luar kilang dengan buangan air kotor dari dalam kilang sangat penting untuk dilakukan.

Limpasan banjir pada saluran drainase pada saluran drainase terjadi jika jumlah air yang masuk kedalam saluran lebih besar dari kapasitas saluran dan terdapat hambatan dalam pengalirannya (Sulardi, 2017). Fokus sistim pengendalian limpasan banjir adalah menyediakan saluran drainase sesuai limpasan aliran yang dating dari daerah tangkapan air dan mengalirkan ke oufall dengan sesegara mungkin (Sulardi, 2016). Adanya hambatan pengaliran berupa sedimentasi, bangunan penghalang dan sudut belokan yang terlalu kecil agar mendapatkan perhatian untuk segera diperbaiki untuk menormalisasi saluran. Jenis aliran pada saluran drainase dibedakan berdasarkan spesifikasi dan kandungan yang terdapat dalam aliran tersebut. Aliran air kotor yang terkontaminasi dengan minyak dan bahan-bahan kimia kecenderunganya dapat merusak bangunan saluran drainase dan memerlukan proteksi tertentu agar saluran tidak mudah rusak. Aliran air permukaan dan air hujan secara alamiah aman untuk langsung dibuang ke perairan umum dan salurannya tidak terinterkoneksi dengan saluran air didalam area kilang karena akan membebani unit pengolah air limbah (effluent water treatment plant). Dengan demikian pemisahan antara aliran air hujan dan air lingkungan dari luar kilang dengan aliran air limbah di area kilang sangat cocok dan sesuai dilakukan sebagai upaya mencegah pencemaran lingkungan air.

Potensi manfaat pemisahan saluran dari luar kilang dan dari dalam kilang meliputi manfaat dari aspek panca mutu quality, cost, delivery, safety dan moral. Dari aspek quality kegiatan ini (1) dapat mencegah potensi pencemaran lingkungan perairan (2) upaya kepatuhan terhadap UU PPLH No. 32 Tahun 2009. Dari aspek cost perubahan ini bermanfaat (1) Upaya mencegah potensi tuntutan denda pelanggaran UU PLH sebesar Rp 5.000.000.000,00 (2) Menekan potensi biaya tambahan untuk bahan, peralatan dan operasi EWTP sebesar Rp 100.000.000,00. Dari aspek delivery perubahan memberikan manfaat (1) Mencegah limpasan banjir diarea kilang selatan (2) Kemudahan penanganan limbah air kotor pada oil catcher dan EWTP. Dari aspek safety perubahan bermanfaat untuk (1) Tersediannya fasilitas handling aliran air hujan dan air permukaan secara terpisah dengan aliran air limbah di dala kilang (2) Buangan air hujan dan air permukaan lainnya dapat dibuang langsung ke perairan bebas. Dari aspek moral perubahan ini memberikan manfaat (1) Pekerja konfiden, inovasinya memberi manfaat dan dapat mengatasi permasalahan dilingkungan kerja dengan baik dana man (2) Company image 
terhadap Pertamina baik dengan sistim penanganan limpasan air hujan, air permukaan dan upaya ketatuhan terhadap UU PPLH No.32 tahun 2009 (UU No.32 Tahun 2009).

\section{KESIMPULAN}

Dari uraian permasalahan, metode penelitian dan hasil pembahasan dapat disimpulkan beberapa hal sebagai berikut (1) Faktor dan penyebab limpasan banjir kilang Pertamina Balikpapan adalah faktor alat, yakni dimensi dan konfigurasi saluran drainase yang tidak sesuai serta masih tergabungnya saluran pembuangan air dari luar kilang dengan saluran air untuk dalam kilang (2) Metode perbaikan yang dilakukan adalah dengan (a) melakukan pemisahan saluran air dari luar kilang dibuat terpisah dengan saluran air buangan dari dalam kilang dan (b) modifikasi saluran eksisting dengan dimensi dan konfigurasi saluran yang sesuai (3) Metode pemisahan saluran dari luar kilang dan dari dalam kilang terbukti efektif dan cocok digunakan untuk mencegah dan mengendalikan limpasan banjir di area kilang utara.

\section{REKOMENDASI} berikut:

Selanjutnya dari hasil-hasil penelitian ini dapat direkomendasikan beberapa hal sebagai

1. Untuk penentuan faktor penyebab permasalahan sejenis yang dianggap cocok dan sesuai adalah dengan metode tulang ikan (fish bone), sedangkan penentuan penyebab yang dianggap paling cocok dan sesuai adalah dengan metode pertanyaan lima mengapa ( 5 why's)

2. Metode pemisahan saluran air dari luar kilang dan aliran air limbah dari dalam kilang penting dilakukan sebagai upaya untuk mencegah pencemaran lingkungan perairan dan kepatuhan terhadap regulasi lingkungan.

\section{DAFTAR PUSTAKA}

Departemen Pekerjaan Umum Republik Indonesia. (2014). Peraturan Menteri Pekerjaan Umum No. 12/PRT/M/2014, Penyelenggaraan Sistim Drainase Perkotaan, Departemen Pekerjaan Umum, Jakarta.

Kodoatie, R. J. \& Sjarief, R. (2010). Jurnal Teknik Sipil Dan Lingkungan Vol. 2, No. 4 (dalam M.A Nugraha), Desember 2014.

Linsley, R.K dan Franzini, B.B. (1988). Teknik Sumber Daya Air Jilid. 1 dan Jilid 2 (Terjemahan. Djoko Sasongko), Erlangga, Jakarta.

Sulardi. (2012). Mengatasi Limpasan Banjir Area Kilang Utara Dengan Temporary Sump pit dan Pompa Banjir Manual Di Pertamina RU V Balikpapan, http://ptmkpwab81.pertamina.com/komet/searchResult.aspx?ptm,Kodefik.AB 12031092.

Sulardi. (2013). Modifikasi Saluran Drainase Crossing Jalan Minyak Dengan Box Culvert Berdasarkan Data Banjir Kilang Juli 2009 Pertamina RU V Balikpapan, http://ptmkpwab81.pertamina.com/komet/searchResult.aspx?ptm,Kodefik. AB 13041012.

Sulardi. (2014). Mengatasi Limpasan Banjir Kilang Area Utara Dengan Metode Redimensi Saluran Outfall Karang Anyar Di Pertamina RU V Balikpapan, http://ptmkpwab81.pertamina.com/komet/searchResult.aspx?ptm,Kodefik.AB 14071039.

Sulardi. (2015). Mengatasi Limpasan Kilang Area Selatan Dengan Metode Pemisahan Aliran Dari Komperta Dubbs, Komperta Pancur dan APT Dengan Metode Pemisahan Saluran Di Pertamina RU V Balikpapan, 
http://ptmkpwab81.pertamina.com/komet/searchResult.aspx?ptm,Kodefik.AC 15092072.

Sulardi. (2016). Peta Banjir Kawasan Karang Anyar dan Komplek Perumahan PT. Pertamina RU V Parikesit, http://ptmkpwab81.pertamina.com/komet/searchResult.aspx?ptm,Kodefikasi.16041172.

Sulardi. (2017). Modifikasi Saluran Drainase Komperta Parikesit Dengan Box Culvert Interkoneksi Saluran Induk Outfall Karang Anyar, Portal Komet Pertamina, http://ptmkpwab81.pertamina.com/komet/searchResult.aspx?ptm,Kodefikasi.17041002.

Sulardi KM. (1997). Aspek dan Strategi Dalam Pengendalian Banjir, Suara Kaltim, Balikpapan.

Undang-Undang Republik Indonesia Nomor 32 Tahun 2009. (2009). Perlindungan dan Pengelolaan Lingkungan Hidup (PPLH), Sekretariat Negara Republik Indonesia. 